International Journal of Electrical Engineering and Technology (IJEET)

Volume 12, Issue 9, September 2021, pp. 1-8, Article ID: IJEET_12_09_001

Available online at https://iaeme.com/Home/issue/IJEET?Volume $=12 \&$ Issue $=9$

ISSN Print: 0976-6545 and ISSN Online: 0976-6553

DOI: https://doi.org/10.34218/IJEET.12.9.2021.001

(C) IAEME Publication

Scopus Indexed

\title{
A STUDY ON THE UTILIZATION OF BIG DATA AND SMART FARM FOR SUCCESSFUL 6TH INDUSTRY AND THE DEVELOPMENT OF PROFESSIONAL HUMAN RESOURCES
}

\author{
Seung-hwan, Jang ${ }^{1}$ and Ju han, Yeon ${ }^{2 *}$ \\ ${ }^{1}$ Assistant Professor, Chamirisa Liberal Arts College, \\ Duksung Women`s University, Seoul, Korea \\ ${ }^{*}$ Professor, College of Business and Management of Technology, \\ Chungbuk National University, Cheongju, Korea \\ *Corresponding Author
}

\begin{abstract}
Korea's agriculture is facing a crisis due to the expansion of market opening, the decrease in agricultural population, and the aging population. In this situation, the need for a "6th industry" to revive the economy of agriculture is emphasized by the convergence of agricultural-based primary industries, secondary industries and tertiary industries. As a solution to the agricultural problem, it is urgent to improve production and reduce labor through automation, and smart agriculture, which combines IoT technologies, is suggested as a solution. It is also necessary to provide customer demand information for each industry for the 6th industry through the convergence of big data technologies. With the application of the fourth industrial revolution technology to our agricultural sector, all fields from production to distribution and consumption are changing, and new ICT technologies centered on the Internet of Things are actively introduced in the precision agriculture sector centered on smart farms. Under these circumstances, it is no exaggeration to say that the success or failure of the 6th industry in agriculture depends on the professionalism of the workforce and the securing of the professional workforce. Therefore, this study intends to examine big data and smart farms for the successful 6th industry and provide implications for fostering professional human resources necessary for them.
\end{abstract}

Key words: 6th Industry, Smart Farm, Big Data, Human Resources

Cite this Article: Seung-hwan, Jang and Ju han, Yeon. A Study on the Utilization of Big Data and Smart Farm for Successful 6th Industry and the Development of Professional Human Resources. International Journal of Electrical Engineering and Technology (IJEET). 12(9). 2021, pp. 1-8.

https://iaeme.com/Home/issue/IJEET?Volume $=12 \&$ Issue $=9$ 


\section{INTRODUCTION}

In recent years, our agriculture has faced a continuing deterioration in the agricultural base due to increased competition due to climate change and market opening, continued decline in the area of agriculture, rapid aging of agricultural population, increased costs and stagnant sales prices.

Our agriculture must create a synergy effect through convergence of agricultural resources and technology by creating new growth engines through the convergence of Information and Communication Technology (ICT) and Biotechnology (BT), which are diverse and intangible local resources, historical and cultural resources, social resources, and human resources.

Therefore, agriculture's 6th industry, which links processing, distribution and service industries based on agricultural production as a methodology for agricultural management innovation, is one of the important strategies for increasing value added and creating jobs through convergence between primary, secondary and tertiary industries.

In other words, agriculture's 6th industry combines the primary, secondary, and tertiary industrial functions of agricultural resources, and it is a new growth strategy that can solve agricultural issues by organically linking newly developed technology and agriculture and contribute to growth and job creation at a national level.

Based on the tangible and intangible primary resources of rural areas, the 6th industry can be defined as an industry that creates new values by combining manufacturing and processing secondary industries and tertiary industries of tourism and experience (Nural Development Administration, 2014). Currently, there are attempts to apply the concept of the 6th industry to various fields related to the 6th industry in terms of economic ripple effects (Shin, 2018).

However, it has various problems such as developing the capabilities of aging local residents and communicating with organizations scattered in the region. In addition, our agriculture is currently in a situation where it is difficult to proceed with the 6th industry only with resources inside the region due to lack of productivity and competitiveness due to aging and others (Kim, 2014).

Therefore, it is important to integrate and share logistics flows leading to primary, secondary, and tertiary industries and information that exists individually in each industry using ICT technologies and to identify more accurate consumer needs and demand forecasting information through big data analysis.

Therefore, in order to overcome the problems of agriculture and enhance the vitality of agriculture, it is imperative to establish the 6th industrialization of agriculture, use ICT and BT's convergence technology, active investment in smart agricultural technology development, and introduction of regulatory reform.

In other words, there is a need to converge ICT and BT technologies in various fields of agriculture and convert the paradigm to smart agriculture based on automation and big data to create new sources of income.

Under these circumstances, the 6th industry of agriculture requires more depth of expertise from agricultural management than ever before. As a new level of agricultural management techniques, technologies, and proficiency are required, it may be difficult to handle from the perspective of agricultural management companies that have been operating mainly on agricultural production activities. In many cases, innovation into a more organized management system is required, and not only management and financial capabilities, but also the use of detailed professional personnel such as marketing, public relations, patents, design, tourism and experience, product planning and development, quality management, food processing processes, and customer service. 


\section{THEORETICAL BACKGROUND}

\subsection{6th Industry}

The 6th industry is a combination of 1st (production), 2nd (processing), and 3rd (selling), and the key concept is to create more added value by combining each industry comprehensively (Kim et al., 2020).

It is time for Korea's agriculture to overcome these difficulties due to problems such as aging, decreasing demand, and weak distribution structure, and external factors such as opening the market (Lee \& Lee, 2019).

Based on government-led efforts, Korea's 6th industry is planning to provide customized support differentiated to the early and mature stages, and is pushing for the introduction of the 6th industrial business certification system, expansion of rural experience, and fostering leading companies.

However, the size of farmhouse management in South Korea is smaller than that of developed agricultural countries, the land is dispersed, and the production aspect of agriculture has been overly emphasized. As a result, added value and jobs derived from agriculture were transferred to cities, which led to stagnant or reduced agricultural growth (Kim \& Heo, 2011).

This in turn constitutes a vicious cycle that causes problems of shrinking agricultural primary production industries and weakening competitiveness. These problems are found to be weak in the first, second, and third industries of Korea's rural areas in the process of 6th industrialization of agriculture, leading to a situation where it is difficult to proceed with the 6th industries alone.

In reviewing the studies on the 6th industry, the 6th industry was emphasized to promote marketing in rural areas (Ryu et al., 2002), and the 6th industry of agriculture was established (Kim et al., 2013). In addition, overseas cases and systems related to the 6th industry were analyzed (Kim et al., 2011), and recently, a case study has been conducted in a specific area to promote the 6th industry (Lee, 2019).

Under these circumstances, in today's complex and uncertain market, the 6th industry is a structure of agricultural-based production, processing, distribution and tourism, so successful 6th industries require big data analysis information.

\subsection{Big Data}

Big data is a large set of structured or unstructured data that goes beyond the ability of traditional database management to collect, store, manage, and analyze data, and extract value from these data and analyze results (Manika \& Chui, 2011).

While the amount of data generated in the analog era was limited, the recent strong activation of the Internet environment has rapidly accelerated and diversified the information users encounter (Suoniemi et al., 2020).

Big data means quantitative meaning of large amounts of data, but if analyzed through text mining, it is good for identifying people's perceptions and trends, so it can be applied to explore customer behavior and choices and predict the future (Mcfia et al., 2012).

The analysis methods of big data can be divided into six main categories. The first is the method of finding interesting associations between variables in vast amounts of data with 'Association tile learning', and is usually used with sales data. The second analysis is 'Classification tree analysis', which identifies the categories to which new observations belong, and requires a data set of correctly identified observations. The third method of analysis is 'Genetic algorithms', which is used to optimize mechanisms such as mutations or natural selection, for efficiency purposes. The fourth analysis method includes software that can be 
learned using data as 'Machine learning' and focuses on predicting the future based on previously known attributes. The fifth analysis is 'Sentimental analysis', which helps judge a person's emotions, and the last 6th analysis is 'Social network analysis', which analyzes the relationship between multiple targets and analyzes the overall structure and influence. The most useful analysis derived from social network analysis is semantic network analysis (Kwak, 2017).

\subsection{Smart Farm}

The history of Korean agriculture began with traditional agriculture and practice agriculture, which applied basic inputs such as land, labor, and capital before modernization. In the 1970s, agricultural modernization led to the advancement of agricultural technology and the development of chemical farming methods by expanding the use of fertilizers, pesticides, and agricultural machinery, and the rapid increase of production through the dissemination of new technologies such as precision agriculture in the 1990s. Since then, the development of 4th Industrial Revolution-based technology and biotechnology technology has been applied to our lives by applying technologies such as artificial intelligence and big data, which led to the development of traditional agriculture such as smart farm, smart agriculture, and precision agriculture. Data-based agriculture is a source of hyperconnected intelligence revolution triggered by digital technologies such as artificial intelligence and big data, and the importance of agricultural data is increasing day by day.

As a solution to this agricultural problem, it is urgent to improve production and reduce labor through agricultural automation, and smart agriculture, which combines IoT technologies, is suggested as a solution. Smart farming is called smart farms and precision farming, and databased farming allows young farmers and returnees who are not familiar with agriculture to continue their successful farming activities through data even if they do not have deep knowledge. These successful cases are suggested as a solution to securing labor in rural areas due to the increase of new young farmers and returnees. Smart agriculture is applied to horticulture, fruit and livestock sectors and is primarily aimed at improving production and reducing labor through IoT-based data collection and analysis (Kim, 2018).

Smart agriculture refers to agriculture that operates on a data-based basis (Nam, 2020), and research and development is being conducted worldwide. Advantages of smart agriculture include reducing costs, reducing inputs, linking agricultural value chains, reducing agricultural risks, and fostering smart agricultural workers (Lee, 2019). The introduction of smart farms is to increase non-farm income by improving agricultural income and utilizing surplus labor for increasing production, improving quality, reducing labor, and simple farming. In the end, the goal is to increase farm income by increasing agricultural income and non-agricultural income (Ministry of Agriculture, Food and Rural Affairs, 2016).

The biggest feature of smart farms is to maximize productivity by using IT technology and optimizing labor and energy needed for agriculture. Therefore, the global agricultural market is expected to bring smart farm technology, and some predict that the smart farm market will also grow rapidly.

\section{UNDERSTANDING BIG DATA AND SMART FARMS FOR THE 6TH INDUSTRY}

The 6th industry is a structure consisting of agricultural-based production, processing, distribution, and tourism, and require big data analysis information in each industry. Growing agricultural products require a period of about a year, and due to poor demand forecasts, prices 
have plummeted or skyrocketed every harvest season. One failure requires more than a few years of recovery, which remains entirely a farmhouse debt.

If big data is used in the 6th industry, production crops can be selected based on demand prediction information to reduce the probability of failure, inventory management costs by producing agricultural and processed products, and customized promotion and distribution processes for local products.

Consumer needs and trends analyzed based on big data are key information that should be considered at all stages of the primary, secondary, and tertiary industries, and each industry needs to be shared without a hitch.

Convergence with high-tech technologies such as ICT (Information Communication Technology), BT (Bio), and ET (Environment) quickly emerged as solutions to improve agricultural problems such as aging population, reducing manpower and farmland, and reducing proportion of production. High-quality, highly efficient IT-based smart agriculture has emerged as a solution to problems such as reduced labor population and farmland, and climate change, and modern agriculture, under the leadership of developed countries, is expanding to the 6th industry in combination with the primary, secondary and tertiary industries.

Furthermore, detailed ICT convergence technology research by each industry is actively being conducted as convergence with ICT is accelerating across the entire value chain of agriculture, such as production, processing, distribution, and consumption. In the primary industry related to production, smart agricultural production systems (smart farms) including functions to prevent insect damage, plant technologies to monitor and control crops, and intelligent agricultural machines with unmanned control and monitoring systems are being developed and utilized as major industrial technologies.

As for distribution and management support technologies, efforts are being made to develop ICT technologies that can be applied at the same level as industrial products by using bar codes and QR codes, and direct trade of agricultural products using the Internet and mobile devices is becoming common. In addition, the scope of research is steadily expanding due to information management and analysis and customer behavior pattern analysis through technology such as cloud and big data and convergence efforts.

However, from the perspective of the 6th industry, it seems that the development and utilization of ICT technologies for each of the primary, secondary and tertiary agriculturalbased industries is limited. The 6th industry of agriculture is also important for automation and development of each industry in the region, but convergence between industries is more important. In addition to the even growth of primary, secondary and tertiary industries within an area, research and utilization of ICT technologies for their convergence are needed more specifically.

Appropriate policies will need to be prepared for this, and the policy proposals are as follows. First, the government should change the direction to establish a smart farm based on automation and big data by applying ICT appropriate to all types of processes (productionoriented, processing-oriented, service-oriented) that promote the 6th industry of agriculture. Second, many management and technical data related to the agricultural sector held by the government should be strengthened information links and expanded information utilization so that real users can access them through various channels. Third, experts in agricultural ICT and SW competitiveness should be expanded. In the case of rural areas, smart agricultural technologies such as small farming and aging should be developed, and the entry barrier should be lowered to compensate for the vulnerability of aging rural populations and allow related human resources to return to farming by allowing young people to farming. Fourth, facilities and technology investments for smart farm farming should be actively made. In other words, facilities and technical investments and education of smart farms should be actively carried out 
so that ICT or IoT can be combined with facility gardening to control temperature, humidity, and amount of sunlight in facilities according to the growing environment of crops and livestock. Fifth, BT technology should rapidly expand the value of agricultural life resources. In other words, BT technology should be combined with agriculture to develop agriculture into new materials and high value-added convergence industries to provide solutions to problems through stable supply of food, national health, welfare, environmental energy, and high-quality agricultural products. Finally, infrastructure should be established for smart agriculture activation. In other words, smart agricultural infrastructure should be established by expanding intelligence-based rural information infrastructure, expanding ICT and BT-related facilities and equipment, establishing high-speed Internet infrastructure, and expanding free Wi-Fi-enabled areas.

\section{UNDERSTANDING THE 6TH INDUSTRY AND PROFESSIONALS}

Professional personnel means 'People who have considerable knowledge and experience in a field and who study or take charge of only that field'. Based on this definition, '6th Industrial Specialist' can be defined as 'a person with expertise and skills to create or enhance added value by combining and providing manufacturing, distribution, and tourism, such as food processing, using tangible and intangible resources such as agricultural, nature, and culture'.

However, there is currently a lack of appropriate statistics or administrative data to identify the status of fostering 6th industrial experts in South Korea. This indicates that the overall social and institutional capability to foster the 6th industrial professional workforce of agriculture is still lacking. Since it has not been long since the 6th industry-related education began, there are insufficient resources for experts and instructors, and there are not many cases of successful management organizations related to the 6th industry in the region. In addition, many of those currently working as experts do not identify the 6th industry based on their understanding of the agro-food value chain, even though they have sector-specific expertise in relation to the 6th industry. In other words, there are not many experts with expertise across the 6th industry.

It is important to establish a consensus within the industry on what capabilities professionals should have in each of the 6th industrial sectors. It is necessary to derive capabilities commonly needed for 6th industrial professionals, special capabilities required by specialized fields, and capabilities that reflect regional characteristics.

Agriculture has a particularly serious low-skilled balance in the workforce sector than in other industries. However, the agricultural 6th industry, which is driven enthusiastically as one of the key strategies for future growth industrialization of agriculture, can be an important opportunity to transform the aging low-wage, low-education-oriented low-skilled balance into a high-skilled balance. In addition to the organization of existing agricultural management organizations to promote the 6th industry, specialized personnel in each field should be supplied by agricultural schools and returning farmers in the form of employment, thereby increasing productivity and increasing value added to create better jobs. In the wake of the 6th industry, the government should transform the low-skilled agricultural industry's manpower structure into a highly skilled balance by systematically supplying professional manpower necessary to enhance the competitiveness of agricultural management companies.

In addition, considering the poor management conditions of the 6th industrialized management, the government should take responsibility for fostering professional personnel and establish and support the system. However, actual related policies and projects should be modified and supplemented to suit regional characteristics, and existing resources should be actively utilized. Local horse The government should establish and operate governance based on the participation of related entities, implement basic plans, and reorganize promotion 
organizations so that 6th industrialization professionals can be fostered to meet the characteristics and needs of agriculture.

\section{CONCLUSION}

As the safety of food is threatened due to weather conditions and environmental pollution, awareness of the importance of safe and fresh food is increasing. Global investors stress that agriculture will emerge as the center of all our lives and become the best future industry. Against this backdrop, the 6th industry of agriculture is coming as a hopeful message.

Because the 6th industry is a convergence of all industries within a region, managing information flow between industries is the most important.

For the promotion of agricultural big data, first, through the expansion of the joint utilization big data platform, the establishment of utilization support system for user convenience and sustainable big data governance should be established. Second, it is necessary to establish a standardization and quality management system to strengthen the management system and capabilities of big data organizations, improve reliability of services.

This allows the following expected effects to be sorted out. First, it will be possible to secure the most important quality data or information through a standardized collection system for accurate data collection, a joint utilization system, and a service operating system. Second, the foundation for data collection/storage, analysis/utilization, etc. can be established through the establishment and operation of a platform that can be jointly used and serviced in the agricultural and food sector. Third, data free zones will allow private companies and agricultural officials to freely analyze, process, and utilize data in the agricultural and food sectors, contributing to the revitalization of the data economy. Fourth, open data trading capabilities implemented in big data platforms will enable companies or individuals to share and trade valuable data. Finally, start-up and service models can be continuously discovered through public data or big data competitions, ultimately creating an atmosphere and laying the foundation for revitalizing the data economy.

The management information system, which utilizes AI, big data, and ICT convergence technologies in the 6th industry, which combines the primary industries (Agricultural and fishery), secondary industries (manufacturing), and tertiary industries (service), will show new opportunities for agriculture in Korea, which is facing limitations, and will have sufficient competitiveness. If it seeks to expand employment through development into related industries and expands into exports using the foundation of global networks as a powerhouse in display and semiconductor manufacturing, it will secure a leading position in global companies and industries.

The collection of agricultural data is an important factor in the development of smart agriculture. The data used in smart farming varies in information types, and it is difficult to utilize and manage data even if it is collected due to different data collection methods and specifications of data for each equipment. Therefore, in order to collect such data, a state-led collection plan should be prepared, and a data collection standard should be proposed by defining the collection specifications for agricultural big data. The definition of standards shall be established as organizational standards and national standards to obtain public confidence and ensure uniformity of items to be collected. In addition, continuous management to improve the quality of data is also an important factor.

However, many of the 6th industrialized agricultural management organizations do not have the various expertise necessary for 6th industrialization because they are operated by loweducated and aging workers. Prior to the industrialization of future growth of agriculture, special measures are needed to transfuse new professionals or develop the expertise of existing ones, even for the sustainability of agricultural management bodies. There is a need to establish 
A Study on the Utilization of Big Data and Smart Farm for Successful 6th Industry and the Development of Professional Human Resources

a specific institutional mechanism and establish an organization dedicated to implementation related to the plan to foster professional workers who will push for the 6th industrialization of agriculture.

\section{ACKNOWLEDGEMENT}

This work was supported by the Industrial Strategic Technology Development Program (p0013990, Convergence technology diffusion type Professional Human Resources Development Project) funded By the Ministry of Trade, Industry \& Energy (MOTIE, Korea)

\section{REFERENCES}

[1] Kim, J.S. (2014), Social innovation to solve rural problems. Science and Technology Policy, 195, 24-36.

[2] Kim, T.S. (2018), Study of smart farm model using big data. Proceedings of Symposium of the Korean Institute of communications and Information Sciences, 1408-1409.

[3] Kim, T.G. \& Heo, J.N. (2011), The 6th industrialization of agriculture and the creation of value added, medium- to long-term promotion of community business (1/3), Korea Rural Economic Research Institute.

[4] Kim, T.G. \& Heo, J.N. \& Yang, C.Y. (2013), Establishment of the 6th industrialization concept of agriculture and how to start a business. Korea Rural Economic Institute Agricultural Focus, 69, 1-29.

[5] Kim, Y.R. \& Heo, J.N. \& Lee, E.K. \& Oh, S.I. (2011), Japan agricultural and fishing village 6th industrialization system guide. Research by the Korea Rural Economic Research Institute, 1135 .

[6] Kwak, K.Y. (2017), Social network analysis. Seoul: Cheongram Publishing Company.

[7] Lee, E.J. \& Lee, C.K. (2019), Estimating the economic impact of tourism industry using bigdata : the case of jongno. Journal of Hospitality and Tourism Studies, 21(1), 31-42.

[8] Lee, J.R. (2019), The S\&T policy study on extension of smart-farming in korea. Science and Technology Policy Institute.

[9] Lee, S.Y. (2019), A Study on the 6th industrialization of the western industrial area fisheries industry. Busan Development Forum, 176, 82-85.

[10] Manyika, J. \& Chui, M. (2011), Big data the next frontier for innovation. Mckinsey Global Institute.

[11] McAfee, A. \& Brynjolfsson, E. \& Davenport, T.H. \& Patil, D.J. \& Barton, D. (2012), Big data: the management revolution. Harvard Business Review, 90(10), 60-68.

[12] Ministry of Agriculture, Food and Rural Affairs. (2016), An analysis and development direction of smart farm operations. Korea Rural Economic Research Institute.

[13] Nam, J.J. (2020), The bare ground smart agriculture, what to do. GS\&J Institute. 